Rehabilitation Research and Training Center for Economic Research on Employment Policy for Persons with Disabilities

Policy Brief

\title{
Dismantling the Poverty Trap: Disability Policy for the 21st Century
}

David C. Stapleton

Bonnie O'Day

Gina A. Livermore

Cornell University Institute for Policy Research

Andrew J. Imparato

American Association of People with Disabilities 
For further information about this paper contact:

Bonnie O'Day

Cornell University Institute for Policy Research

1341 22nd Street, NW

Washington, DC 20037-3010

tel (202) 223-7670

emailbo29@cornell.edu

web www.cuipr.cornell.edu

This Policy Brief is being distributed by the Rehabilitation Research and Training Center for Economic Research on Employment Policy for Persons with Disabilities at Cornell University.

This center is funded to Cornell University, in collaboration with The Urban Institute (Washington, DC), by the U.S. Department of Education, National Institute on Disability and Rehabilitation Research (No. H133B980038). The contents of this paper do not necessarily represent the policy of the Department of Education, and you should not assume endorsement by the Federal Government (Edgar, 75.620 (b)). The views in this policy brief are not necessarily endorsed by Cornell University or the American Association of People with Disabilities.

The Co-Principal Investigators are:

Susanne M. Bruyère—Director, Employment and Disability Institute, School of Industrial and Labor Relations, Extension Division, Cornell University

Richard V. Burkhauser-Sarah Gibson Blanding Professor and Chair, Department of Policy Analysis and Management, College of Human Ecology, Cornell University

David C. Stapleton—Director, Cornell University Institute for Policy Research 


\section{Introduction}

Working-age Americans with disabilities are much more likely to live in poverty than other Americans and generally did not share in the economic prosperity of the late 1990s. At the same time, public expenditures to support them are growing at a rate that will be difficult to sustain when the baby boom generation retires and begins to draw Social Security Retirement and Medicare benefits. We argue that this discouraging situation will continue unless we can bring disability programs into line with more contemporary understanding of the capabilities of people with disabilities and successfully implement broad, systemic reforms to promote their economic self-sufficiency. This policy brief summarizes a larger paper (Stapleton, O’Day, Livermore \& Imparato, 2005). It suggests principles to guide reforms and encourage debate. Future policy briefs will elaborate on some of these principles.

\section{Dependence on Public Programs is Growing and People Still Live in Poverty}

The employment rate of working-age people with disabilities is about half of the employment rate of working-age people without disabilities, regardless of what national survey is used or how disability is measured. According to the American Community Survey conducted by the U.S. Bureau of the Census, 38 percent of working-age people with at least one disability were employed in 2003, compared with 78 percent of people reporting none of the disabilities measured by the survey (Weathers 2005). Poverty rates for people with at least one disability are more than twice as high as for those with no disabilities (See Figure 1).

The fact that people with disabilities are falling further behind others economically is not due to a decline in public expenditures for their support. In fact, almost nine million working-age adults with disabilities receive income support from the Social Security Disability Insurance (SSDI) and Supplemental Security Income (SSI) programs; about $\$ 87.3$ billion is currently being spent on these programs annually. Rather, the poverty rate and quality of life of beneficiaries has not significantly improved despite ever increasing expenditures (Burkhauser, Houtenville \& Rovba, 2004; Burkhauser, Daly \& Houtenville, 2001; Burkhauser \& Stapleton, 2003; Burkhauser \& Stapleton 2004). This is partly because benefits are often insufficient to lift incomes above the poverty standard (the maximum federal SSI benefit is now only about 75 percent of the federal poverty standard for an individual), partly because many people with disabilities do not receive support from these programs, and partly because people who are on benefits are often unable to add to these benefits by working.

\section{Today’s Support Policies Create a Poverty Trap}

Today's income support policies are built on the obsolete premise that people with particular disabilities cannot work, and therefore must rely on others for support. These policies create a poverty trap for many people with disabilities. An initial critical component of the poverty trap is that when people apply for Social Security disability benefits (either SSI or SSDI), they must demonstrate that they cannot work by not working. A second component involves the rules that sharply reduce benefits as a beneficiary's earnings increase. SSDI beneficiaries are able to earn up to the Social Security Administration's (SSA's) substantial gainful activity (SGA) level each month (\$830 for SSDI non-blind beneficiaries, and \$1,380 for 
blind beneficiaries in 2005) without losing any benefits, but if earnings exceed that amount by as little as one dollar for nine months or more, the beneficiary faces the "earnings cliff" where all SSDI cash benefits are lost. For those with benefits in excess of SGA, the income loss can actually be greater than the individual's earnings. Beneficiaries who return to work within the first 24 months also lose the opportunity to qualify for Medicare coverage, which is provided 24 months after the individual is found eligible for SSDI.

The SSI recipient faces a different constraint; after earnings reach \$65 per month, benefits are reduced by one dollar for every two dollars of additional earnings. Put differently, the SSI recipient's income is implicitly taxed at a rate of 50 percent - a tax rate that is higher than that paid by even the wealthiest individuals. Many may also face reductions in food stamps, housing subsidies, and other assistance as their earnings increase.

Another significant component of the poverty trap is the sheer complexity and poor coordination of support systems for people with disabilities. The many in-kind supports that are available to people with disabilities are administered by a variety of state and federal agencies and private organizations, each with its own rules, many of which are very complex in their own right and take a great deal of time to understand. Each additional program improvement seems to add to, not remove, this complexity. As Oi (1978; 1992) says, “Disability steals time.” The gross inefficiency of our current support system steals even more.

The final key element of the poverty trap is the self-fulfilling expectation, ingrained in the support system, that people with disabilities cannot support themselves, or perhaps worse, may come to believe that they cannot contribute to their own support through working.

In this policy environment, many individuals with significant functional limitations and relatively low earnings capacity face the following choice. They can work, receive wages, perhaps obtain some in-kind supports, and live in or near poverty. Or, they can severely limit their work, navigate the support system, and receive income and in-kind benefits that also leave them in or near poverty. They are trapped. The problem is not that the benefit levels and supports are too generous; it is that low-wage beneficiaries need a gradual reduction in benefits and the provision of some in-kind supports to make employment pay off. A successful economic selfsufficiency policy would create greater incentives and opportunities to escape poverty.

\section{The Transition to Economic Self-sufficiency Policy is Already Under Way But Has Been Largely Ineffective}

It has been more than thirty years since the beginning of the independent living movement, and the idea of people with disabilities living, working, and participating in their communities has become the expectation and goal of many current programs and policies. In 1999, the Ticket to Work and Work Incentives Improvement Act (“Ticket Act”) provided for additional choice in rehabilitation providers and additional incentives for people to work and leave the benefit rolls. More recently, President Bush has developed the New Freedom Initiative, a nationwide effort to remove barriers to community living for people with disabilities and long-term illnesses. There have also been recent bipartisan efforts to encourage low-income populations, including low-income people with disabilities, to improve their financial literacy and to acquire assets. These kinds of savings programs, when coupled with an earned income 
stream, can help to address the long-term poverty that many Americans with disabilities currently experience.

Despite the intent of these current policy reforms and initiatives, it seems unlikely that they will achieve substantial progress toward greater economic self-sufficiency of people with disabilities and a higher standard of living for three reasons: first, these policy reforms do not adequately address work disincentives; second, they increase the already excessive complexity of the current support system rather than reduce it; and third, they fail to address the unrealistically low expectations of the work capacity of individuals with disabilities when appropriate supports are provided.

Thus far, policymakers have taken a piecemeal approach toward policy changes that will promote economic self-sufficiency and increase the standard of living for people with disabilities. We try to at least partially correct specific problems with specific programs, without addressing the many other problems that need to be corrected. We are adding complexity to the programs, making them even harder to administer, and failing to address their long-term fiscal health.

\section{To Be More Successful, Policy Reforms Must Include Several Key Features}

To make significant progress, it will be necessary to develop and implement system-wide reforms that fundamentally change support policies by replacing today's obsolete policies that promote program dependence with policies that promote economic self-sufficiency. We suggest an overarching goal, and related principles to guide reforms. We also strongly emphasize a holistic approach to policy reform, which we believe is necessary to make real and lasting change that empowers millions of people with disabilities to escape poverty.

Our system-wide goal is maximum economic self-sufficiency at a reasonable standard of living for every person facing a significant challenge to employment because of functional limitations. We list below some of the principles to guide such policy reform, but acknowledge the complexity of such sweeping systemic reforms and the trade-offs inherent in some of the policy choices these principles present.

Sustainable: The system must be designed to obtain the long-term public support of the voters and key interest groups. In all likelihood, growth in public expenditures will need to be reduced. As importantly, the system would have features that voters generally support, such as personal responsibility for one's own actions and well-being, efficient use of public resources, and equitable distribution of benefits.

\section{System-wide eligibility criteria designed to identify people with significant functional} limitations: This is defined in the International Classification of Functioning, Disability, and Health (ICF) as a significant deviation or loss in body physiology or structure, such as loss of sensation in extremities, visual or hearing loss, paralysis, or anxiety (World Health Organization, 2001). Although some medical criteria will be needed to define who is eligible for any supports from the system, eligibility criteria should move toward a functional definition of disability; they should not include a work test or be designed to determine inability to work. Program eligibility should be broadly defined, enabling eligible individuals to easily obtain the supports they need at 
any period in time. Decisions about which supports an individual receives would be separated from the eligibility decision. Waiting periods for support would be eliminated.

A rebuttable presumption of ability to work: The presumption would be that, with appropriate supports, all eligible individuals can work and at least partially support themselves, despite the challenges posed by a given individual's functional limitation. This principle recognizes that significant numbers of beneficiaries will work only part-time or intermittently. This presumption could be automatically rebutted for those with the most severe impairments, but others would be expected to make good faith efforts to work over an extended period, after which some might be classified as completely unable to work. We strongly emphasize that this principle should not be adopted in isolation of the other principles listed. So doing would cause great harm to many people with disabilities.

Early intervention: Early and timely efforts would be made to provide supports that will likely lead to successful entry into the workforce for first-time workers, and continuation of employment for workers adjusting to disability onset or exacerbation.

Beneficiary and program responsibility to achieve program goals: Beneficiaries of system supports would be expected to take reasonable actions that contribute to their own support and would be held responsible for doing so. For those who have not rebutted the ability to work presumption, this would include work effort requirements. Program administrators and staff would be held to a similar standard. The effort to help beneficiaries achieve economic selfsufficiency and a reasonable standard of living, and the success of their effort, would be important criteria in assessing their performance.

Incentives that make work pay: Those able only to attain low-wage jobs or to work parttime or intermittently would receive wage subsidies or tax credits that would both provide them with an incentive to work, save money, acquire assets, and improve their standard of living.

Supports for those who cannot attain a reasonable standard of living without them: Those who rebut the presumption of ability to work or who can only work part-time or intermittently would be eligible for income and in-kind benefits that are sufficient to provide them with a reasonable standard of living, considering any disability-related expenses they incur. Those for whom earnings and incentive payments are insufficient to attain a reasonable standard of living would receive levels of support intended to bring their income up to the standard established as reasonable.

Access to health care and assistive technology that is not linked to employment: To remove availability of health care as a work disincentive, eligible individuals, particularly those with chronic conditions, who require personal assistance, or who need ongoing mental health services, should have access to assistive technology or other long-term services, without regard to their employment status. Individuals with impairments who are currently working would be eligible for health insurance, assistive technology, and other supports to enable them to avoid job loss, without regard to their eligibility for cash benefits. Although income levels would be considered in determining the amount of individual subsidies, no one would be made worse off by working. 
Other supports that are well-coordinated, encourage work, are easy to navigate, are tailored to the individual's needs, and are efficiently delivered: Individuals would access support services through a single point of entry in the system rather than separately from multiple agencies and administrators. Supports would not be contingent on work except to the extent that they are needed to support work. Providers would be paid through a system that encourages them to efficiently meet the needs of the individual. Individuals with incomes in excess of that needed to support a reasonable standard of living would be expected to pay for some share of the services. Employers would be expected to contribute to the extent that such services might substitute for benefits they would provide to other workers (e.g., for health insurance) or for expenses that would fall under the ADA's "reasonable accommodation" requirement for covered employers.

Incentives for people with disabilities to improve their financial literacy, save money, acquire assets, and make investments: Beneficiaries would receive incentives to save money and use assets and investments as a tool to escape poverty.

Substantial beneficiary control over the delivery of supports: Beneficiaries and their agents/representatives would have a high degree of control over the delivery of supports. For instance, when feasible they would be allowed to choose providers, and some options would allow them to obtain services without interrupting work activities. Support staff would be available to assist individuals, particularly those with cognitive disabilities, in managing services and making choices.

Support services delivered in integrated settings: To the extent practical, people with disabilities would receive support services (e.g., health care, education, training, job search, and transportation) from the same providers that deliver these services to others.

Recognition of the ongoing effects of disability discrimination in the workplace: Qualified workers who fail to find work or lose a job because of discrimination should not be unfairly penalized by benefit loss.

Conduct an extensive public awareness campaign: An extensive public awareness campaign about the work capabilities of people with disabilities, similar in scope to recent antidrug campaigns, will be necessary if policy reform is to be effective. Among others, leaders in business and government must recognize that tapping into this available and largely underutilized labor source is an important opportunity, as well as one of the most significant challenges facing the U.S. economy.

The transition to economic self-sufficiency policy has already begun. The questions are how it will occur, how fast it will occur, and how much progress will be achieved. Our goal is greater economic self-sufficiency and a higher standard of living for people with disabilities. That is the issue that challenges us today, and that requires a full and open debate. 
Figure I: Employment and Poverty Rates by Disability Status, 2003

Employment Rate

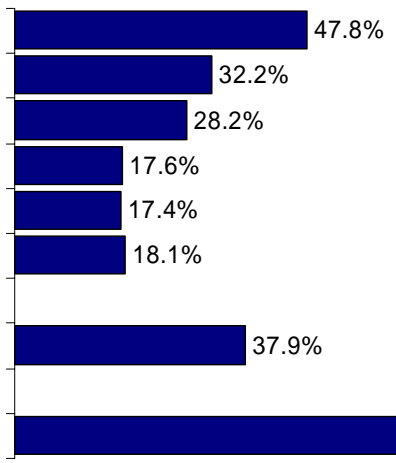

Source: Weathers (2005).
Poverty Rate

Sensory Disability
Physical Disability
Mental Disability
Self-care Disability
Go-outside-home Disability
Employment Disability
Any Disability
No Disability

Sensory Disability

Physical Disability

ental Disability

Go-outside-home Disability
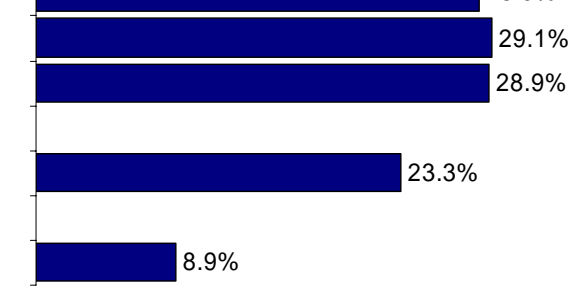


\section{References}

Burkhauser, R.V., Daly, M.C., Houtenville, A.J. \& Nargis, N. (2002). Self-reported work limitation data: What they can and cannot tell us. Demography 39(3), 541-555.

Burkhauser, R.V., Houtenville, A.J., \& Rovba, L. (2004). Rising Poverty in the Midst of Plenty: The Case of Working-Age People with Disabilities in the 1980s and 1990s. Ithaca, NY: , Cornell University, Rehabilitation Research and Training Center for Economic Research on Employment Policy for People with Disabilities.

Burkhauser, R.V. \& Stapleton, D.C. (2004. The decline in the employment rate for people with disabilities: Bad data, bad health, or bad policy? Journal of Vocational Rehabilitation 20(3), 185 $-201$.

Burkhauser, R.V. \& Stapleton, D.C. (2003. Chapter 1: Introduction. In D.C. Stapleton, \& R.V. Burkhauser, (Eds.). The decline in employment of people with disabilities: A policy puzzle (pp. 121). Kalamazoo, Michigan: W.E. Upjohn Institute for Employment Research.

Oi, W. (1978 October). Three paths from disability to poverty. (Technical Analysis Paper No. 57), Washington, D.C.:U.S. Department of Labor, ASPER.

Oi, W. (1992 September). Work for Americans with disabilities. In H. Orlans, \& J. O'Neill, (Eds.) Annals of the American Academy of Political and Social Science. (pp. 159-174). Thousand Oaks, CA: Sage.

Stapleton, D.C., O’Day, B, Livermore, G.A., \& Imparato, A. J. (2005). Dismantling the Poverty Trap: Disability Policy for the $21^{\text {st }}$ Century. Working paper. Cornell University Rehabilitation Research and Training Center for Economic Research on Employment Policy for People with Disabilities.

Weathers, R. (2005). A User Guide to Disability Statistics from the American Community Survey. Ithaca NY: Rehabilitation Research and Training Center for Disability and Demographic and Statistics, Cornell University.

World Health Organization. (2001). International Classification of Functioning, Disability and Health. Geneva: World Health Organization. 
For more information about the Cornell RRTC contact:

Susanne M. Bruyère, Ph.D., CRC

Project Director

201 ILR Extension Building

Cornell University

Ithaca, NY 14853-3901 tel (607) 255-9536

fax (607) 255-2763

TDD (607) 255-2891

e-mailssmb23@cornell.edu

web www.ilr.cornell.edu/rrtc 